\title{
Study on the Humanitarian Spirit in the Folk Narration of Chinese Contemporary Photography
}

\author{
Bing Hao \\ Henan University Minsheng College \\ Kaifeng, Henan, China 475001
}

\begin{abstract}
The contents such as caring human life, concerning about human fate, reflecting the human living status reflected by the relations between human and human and human and environment, etc are the subjects of documentary photography. Similarly, the documentary photography from the folk perspective also focuses on life and society and embodies the strong sense of social responsibility and humanitarian spirit. The subject of Chinese humanitarian spirit is a kind of wide and open concept. On the contents, it involves the compassion feelings about the life suffering of insulted or hurt people, defending of humanity and the liberation of individuality, affirmation and call on naturality of humanity which not only eulogizes and calls positively but also fustigates and complains passively. Photography is taken as the starting point of this thesis, because the 21st century is an era of picture-reading and the pictures have become more and more important in the daily life of human which also possesses intuition on the expression of subject of humanitarian spirit. For the photography creation in humanitarian spirit, as long as the caring and affirmation on human, human dignity and value and humanity can be truthfully or objectively realized in the works, the creation should be taken into the mood projection vision in the subject of Chinese humanitarian spirit in 21 st century.
\end{abstract}

Keywords-Chinese contemporary photography; folk narration; humanitarian spirit

\section{INTRODUCTION}

As a kind of typical narration work, the photography works have received more and more attention from the narrative theory. What is called narration is "the narration on one or more true or imaginary stories". The photography narrates by the camera lens. The camera lens are a pair of eyes and what it can see, what it cannot see, where they start seeing, whether they overlook or look up and other contents are all another kind of potential language different with words.

\section{GENERATION OF FOLK NARRATION OF CHINESE CONTEMPORARY PHOTOGRAPHY}

Narration means to directly tell and complain what is vivid and possesses the capacity of narration. When someone is running, shoot the scene and the photo will tell the readers that someone is running and that is called the narration. Using images to narrate is the most important function of photo. Comparing with its form of art, this is also its most special function.
Just as its name implies, the folk narration is to narrate the living states of common people from the folk perspective. Folk narration is a pretty fashionable and effective method for explanation approved by many researchers of modern and contemporary Chinese literature since 1990s. Those writers take the principle of value of folk culture as their basic standard to distinguish right from wrong or take the folk as their destination for habitat of souls so as to express their cognition and attitude toward politics, society and culture tide which more truthfully and comprehensively reflects the free existence logic of folk culture patterns and the desire of free life. They understand the society, life and politics from the vision of "lower class", comprehend the folk customs and conditions of the people and narrate the psychological connotation, life desire and behavioral pattern of "country folk". This kind of phenomenon possesses clear tendency in the contemporary photography. There are quite many photographers point their camera lens to the present, surrounding and personal truth or to the folk, daily and diversified life details and go deep into the life of folk common people. They look at and intensively exhibit the history from the folk perspective. They aim to restore the original life modes of Chinese people in the measure of images and reflect the living status of common people in abundant, free and polymorphic personalized viewpoints through broad and vivid details.

Since the mid-term of 1980s, the upper regime emphasized the separation of the Party and the government. Until the early 1990s, because the political ideals of one generation is gradually fading away and the reform and opening-up policy focuses on the growth of economic life, the secularistic life of Chinese people can obtain the opportunity and space to recover. Till later 1990s, the political life was gradually backing to the few people in upper class and tended to be professional and the common people no longer had close relations with the upper politics so that the normal life gradually possesses various delicate and abundant details. There are sometimes the hubbub from marketplaces, neighborhoods, towns and villages as well as the simple quietness and fine atmosphere which can only be felt by the family life. Also, this kind of hubbub is the jollification of the folk and masses long-lost in our heart which is just like the crowded conditions in Shehuo and rural plays at festivals and is a kind of rich and natural riot of sound full of vitality. Secondly, this breaks over from an important theoretical support which is the rising of so-called "humanistic care). The spread of this concept sounded to be full of tender 
feeling" is also the contribution of the publishing of two books of Mr. Ruan Yizhong, the popularizing person of Taiwan photography in mainland. While in the mainland, the heated argument on "humanitarian spirit" in mid-term of 1980s also laid the theoretical basis for many photographers to start adhering to this morality standpoint. What's more, as a transitivity strategy of news photography that is intended to get rid of the vulgar political propaganda functionalization, the professional concept of "documentary photography" with ambiguous implication has been well known by people that also provides a professional excuse for the photographers to focus on the objective of such crowd.

In addition, large number of pictures concerning about the living status of vulnerable groups and marginal groups has been continuously introduced to China from foreign countries. The successful illustrative examples where a few of such domestic pictures win big prizes in the world picture competitions- for example, the Psychiatric Hospital of Yuan Dongping wins the award of POY in America, the Child Learning Acrobatics of Li Nan wins big prize in the World Press Photo and later Li Lang, Wang Yao, Zeng Nian, Lu Guang and other photographers win the world-wide photography awards. Those examples truly cause great stimulations to other photographers and they gradually have the illusion that only the shooting and transmission of such pictures can be qualified to be compared with those of others on the world-wide picture platforms. Under such situation, it will be not that difficult understanding why the pictures focus on the vulnerable groups or marginal groups can become a common practice.

\section{MEANINGS AND HUMANITARIAN SPIRIT OF FOLK NARRATION OF CHINESE CONTEMPORARY PHOTOGRAPHY}

The folk narration photography is supposed to belong to the documentary photography because it possesses the nature of documentary photography and possesses the characteristics of itself at the same time. This kind of photography points the camera lens to present, surrounding and personal truths and to the folk, daily and diversified life details which goes deep into the life of common people, displays the history from the folk perspective and aims to restore the original living modes of Chinese people in the measure of images and reflects the living status of common people in the abundant, free and polymorphic personalized viewpoints, provides the Chinese human feeling conditions and manifests the humanistic connotations of a great time.

In such narration, the folk exists against the official, mainstream and elite culture. Its features are emotional, natural, untouched and low-class and uncertain and it possesses rich grass-roots characteristics. The folk narration is a kind of narration measure based on the traditional creation which takes the lands where folk people live as the original shapes and adopts the original ecological narration measures to reflect the actual living; adopts relatively objective attitude to reflect the "humanity" in the measure of folk culture narration and to reflect the original status of human. It is the measure where the photographers with strong social responsibilities and sense of mission inherit the humanitarian spirit and the principle of kindness, go deep into the living reality and truly understand and respect the photography objectives with huge perseverance or even dedication and reappear with the true circumstances in the measure of snapshot with no fiction and disguise.

The folk narration photography generally originates from the individual will and constructs the folk narration that seems to be insignificant to many people in the term of independent and conscious memory which on one hand is to objectively reappear with the original status of life and try to keep the original taste and flavor of life to carve and recover the socalled life with defects; it on the other hand is to manifest the original status of photography objective and start from the content demands, randomly dispatch and make improvisational snapshot to obtain the sense of reality in natural state. The folk is divided into broad and narrow senses; the broad sense means the narrators and the narration contents; while the narrow sense only means the narration objective or narration contents. What is discussed in this thesis adopts the folk narration concept in broad sense. Here, the difference with viewpoint of common people needs to be mentioned which is the narrative perspective that starts from the narrator perspective in the folk narration discourse modes. It only explains photography from the narration perspective while this thesis explains photography from the narration discourse modes.

The human sympathy is the spiritual connotation of folk narration of Chinese contemporary photography and is also the concrete embodiment of the conscience and responsibilities of photographers. The photographers with true sympathy, loving heart and sense of justice will not make vicious explosion and will not stand high above the masses to "overlook". The reason why they manifest the pains, disease, guilty and all the misfortune is to not only manifest the "tremble with sympathy" but also expect to "draw the attention of rescue and cure which will promote the thinking of the person involved and bring the possibility of changing so as to make our world a better place.

The Chinese humanitarian spirit subject is a wide and open concept. On the contents, it involves the compassion feelings to those insulted and hurt, defending of humanity and liberation of personality as well as the affirmation and call to naturality of humanity which not only eulogizes and calls positively but also fustigates and complains passively. Photography is taken as the starting point of this thesis, because the 21 st century is an era of picture-reading and the pictures have become more and more important in the daily life of human which also possesses more intuition on the expression of subject of humanitarian spirit.

The development process of human society is the process of realization and continuous improvement of humanitarian spirit. The humanitarian spirit has different contents in different times. But on the aspect of its development process, the humanitarian spirit emphasizes more and more on the status of human, affirm the value of human, guard the dignity and happiness of human and satisfy the demands and interests of human.

The Chinese humanitarian spirit subject that we are talking about is a wide and open concept. On the contents, it involves the compassion feelings to those insulted and hurt, defending of humanity and liberation of personality as well as the affirmation and call to naturality of humanity which not only 
eulogizes and calls positively but also fustigates and complains passively. On the styles, it includes poems, novels and dramas. Photography is taken as the starting point of this thesis, because the 21 st century is an era of picture-reading and the pictures have become more and more important in the daily life of human which also possesses more intuition on the expression of subject of humanitarian spirit. For the creation in humanitarian spirit subject, as long as the caring and affirmation on human, human dignity and value and humanity can be truthfully or objectively realized in the works, the creation should be taken into the mood projection vision in the subject of Chinese humanitarian spirit in 21 st century.

The photographers of humanitarian spirit try to go through the fog of emotions and directly reach the history and reality. But the sense of mission of enlightenment and the utilitarian of changing the reality usually keep them not that focusing on the skills for artistic expression. Those who possess the humanitarian spirit not only just describe or reflect the issues of "human" and "life" but focus essentially on instructing life and transforming life.

The humanitarian spirit for folk narration photography not only is the concrete embodiment of conscience and responsibilities of photographers but also is the direct result of call of humanitarian spirit of the times. The photographers with true sympathy, loving heart and sense of justice will not make vicious explosion and will not stand high above the masses to "overlook". The reason why they manifest the pains, disease, guilty and all the misfortune is to not only manifest the "tremble with sympathy" but also expect to "draw the attention of rescue and cure which will promote the thinking of the person involved and bring the possibility of changing so as to make our world a better place.

The root for folk narration photography lies in the sincerity. Most of the authors try to express the cause and effect of matters and reveal the meaning of its existence with sincere images. The divergence between them and the tradition is not to be induced by the slogans and fashion and not to be controlled by the direct utility and simple diagrams. They stick with themselves and understand that they cannot find ego in the inducement and self-deception. They will not loudly yell the claptraps such as beauty and impact force of photos and become the megaphone or yesman of politics or money by pleasing or catering to the media. They respect their instincts, respect their eyes and respect their findings so as to abandon the disguise and usage of lame arguments. We can see from their works and photography process that although they are born in the times full of ideals, life still cultivates their true quality of common people and teaches them the common characters of getting to the root of the matter and also provide them with unfathomable experience and decorous feeling and also give them the care and responsibilities to the society at the same time. They control the camera with care and responsibilities and press the shutter to inject humanity sincerity. They keep close to life and look straight at life and keep the civilian vision instinct. They use the humanity viewpoint existing in their natures to care people around, the person orientation and humanity so as to integrate into another kind of images with Chinese characteristics.

\section{CONCLUSION}

Human sympathy is the spiritual connotation of folk narration of contemporary photography and the embodiment of photographers' conscience and sense of responsibility. Photographers with sympathy, loving heart and sense of justice will neither disclose maliciously nor "look down". They show hurt, diseases, sins and misfortunes, in order to express "the pitiful trembling" and hope to "attract treatment and cure", promote parties to think and make our world better. This paper discusses a marked feature in the development of Chinese contemporary photography from the perspective of humanitarian spirit in folk narration of Chinese contemporary photography, in order to help people further understand photography.

\section{REFERENCES}

[1] Luo Gang. Introduction to Narratology [M], Kunming: Yunnan People's Publishing House, 1994

[2] Zhang Qinghua. Flowing Deformation of Folk Conception and Three Folk Aesthetic Forms in Contemporary Literature [J], Literature and Art Studies, 2002-2

[3] Chen Pingyuan. Hero and History: Base on Folk Narration-Discussion on Type of Chinese Novel with Each Chapter Headed by a Couplet Giving the Gist of Its Content in Ming Dynasty [J], Chinese Culture Research, 1996-2.

[4] Zhou Ming, Lin Lu. Discovery and Capture-Folk Narrative Photography in Instant Eternality [M], Shenyang: Liaoning Fine Arts Publishing House, 2002

[5] Hu Wugong. Chinese Video Revolution [M], Beijing: China Federation of Literary and Art Circles Publishing House, 2005

[6] Mo Yan. Writings of Ordinary People [J], Contemporary Writers Review, 2005

[7] Shi Baoxiu. Era Image [M], Guangzhou: Lingnan Fine Arts Publishing House, 2003

[8] Ma Xiaohu. The Forgotten People_-Living Situation of Chinese Mental Patients [M], the Third Library, 1993

[9] Tang Dongping. Analysis on Photography Works [M], Hangzhou: Zhejiang Photographic Press, 2006

[10] (US) Mary Warner Maria, translated by Hao Hongwei and Ni Yang. Photography and Critics of Photography [M], Jinan: Shandong Pictorial Publishing House, 2005

[11] Gong Zhiming. Reading on Contemporary Chinese Photographer [M], Hanzhou: Zhejiang Photographic Press, 2002

[12] (US) Barrett, Criticism on Video Art [M], Shanghai: Shanghai People's Fine Arts Publishing House, 2006

[13] [14](America) W.J.T. Michelle, translated by Chen Yongguo, $\mathrm{Hu}$ Wenzheng. Picture Theory [M], Beijing: Peking University Press, 2006

[14] Lyu Wei, An Deming. Diversity of Folk Narration [M], Beijing: Xueyuan Press, 2006

[15] (Slovenia) Ales Erjavec, translated by Hu Julan and Zhang Yunpeng. Toward the Image [M], Changchun: Jilin People's Publishing House, 2003

[16] (Britain) John Bogle, translated by Shen Yubing. Another Narration Model [M], Guilin: Guangxi Normal University Press, 2007. 